\title{
Gastro-pharyngeal reflux and total laryngectomy. Increasing knowledge about its management
}

\author{
Giuditta Mannelli a,*, Roberto Santoro ${ }^{\text {a }}$, Francesco Segala ${ }^{a}$, Elisabetta Surrenti ${ }^{\mathrm{b}}$, Oreste Gallo ${ }^{\mathrm{a}}$ \\ a Clinic of Otorhinolaryngology, Department of Surgery and Translational Medicine, University of Florence, Via Largo Brambilla 3, 50134 Florence, Italy \\ b Digestive Pathophysiology and Motility Unit, Careggi University Hospital, Florence, Italy
}

\section{A R T I C L E I N F O}

\section{Article history:}

Received 7 September 2017

Available online $\mathrm{xxxx}$

\section{Keywords:}

Gastropharyngeal reflux

Total laryngectomy

$\mathrm{pH}$ monitoring

Impedance monitoring

Proton pomp inhibitor therapy

\begin{abstract}
A B S T R A C T
Purpose: Investigate the incidence, the degree and the effect of gastro-pharyngeal reflux (GPR) in laryngectomised patients.

Materials and methods: Behavioral and 24-hour pH- and impedance-monitoring data were prospectively analyzed for 25 laryngectomised patients with no previous history of GER in outpateints' setting. Reflux detected was characterized as either acid, weakly acidic or nonacid. Proximal reflux was found at $15 \mathrm{~cm}$ above the LES. Results: $40 \%$ of patients presented a pathological number of reflux episodes in the upright position $(\mathrm{p}<0.0001) ; 9$ of them presented a pathologic bolus exposure time. Bolus exposure at the proximal sphincter was one fourthfold lower than $5 \mathrm{~cm}$ above the LES ( $\mathrm{p}=0.3593$ ). There was a prevalence of acid reflux at both sphincters ( $\mathrm{p}$ $<0.0001)$; liquid reflux was prevalent at the LES $(\mathrm{p}=0.003)$ and mixed reflux at the UES $(\mathrm{p}=0.0001)$. Median REs was higher than time acid exposure $(\mathrm{p}=0.0013)$.

Conclusions: Pre- and post-surgical reflux investigation could identify preexisting reflux severity and screen potential high-risk cancer patients for postoperative complications. This might allow the early onset of acid suppressive therapy in presence of pathologic findings in high-complication risk cancer patients.
\end{abstract}

(C) 2017 Elsevier Inc. All rights reserved.

\section{Introduction}

Gastresophageal reflux (GER) consists of the retrograde flow of gastric contents through the lower esophageal sphincter (LES) into the oesophagus, and it is one of the most prevalent health disorders in the Western world, estimated to affect about $20-40 \%$ of the population [1]. GER disease (GERD) is a frequent condition characterized by various manifestations from typical or atypical esophageal symptoms to many extraesophageal disorders [2]. On the other hand, in the gastropharyngeal reflux (GPR) the retrograde flow of gastric acidity reaches pharynx and larynx [3].

There are many reports about the laryngeal and pharyngeal damage caused by gastresophageal acid reflux, suggesting a possible harmful action of pepsin and acid on the upper respiratory airways mucosa [4-7], due to the higher susceptibility of larynx to gastric acid than the esophageal mucosa [8]. On the basis of this susceptibility, authors have been tried to demonstrate a possible independent or adjuvant role of GER

\footnotetext{
* Corresponding author at: University Clinic of Otorhinolaryngology, Department of Surgery and Translational Medicine, University of Florence, Via Largo Brambilla n. 3, CAP 50134 Florence, Italy.

E-mail address: giuditta.mannelli@unifi.it (G. Mannelli).
}

in laryngeal and pharyngeal cancerogenesis, so far [9,10]. Nevertheless, this hypothesis has gained support from a limited number of investigations among laryngeal cancer patients [3,5,10-14]. In this setting, it has been reported about the significant positive association between a history of frequent heartburn and laryngo-pharyngeal squamous cell carcinomas (LPSCCs) among people neither smokers not drinker identifying reflux as independent risk factors for these malignancies [15]; accordingly, a large case-control study showing a higher risk of laryngeal cancer among achlorhydric patients, supports bile regurgitation as harmful agent on laryngo-tracheal mucosa $[1,16,17]$. However, the possible association with reflux does remain enigmatic $[18,19]$ and studies on esophageal squamous cell carcinoma do not support a link with GERD $[11,20,21]$, identifying alcohol and tobacco exposure as confounding factors.

Despite this, it should be pointed out that these regions (i.e.: larynx and pharynx) have no defense mechanisms, unlike oesophagus, thus representing a vulnerable area. A specific condition of altered anatomic defensive barriers could be the result, for example, of laryngeal surgery. In this setting, little is known about the role and the incidence of GER and GPR in causing voice problems, pharyngitis, mucositis and increasing the incidence of post-operative complications in laryngectomised patients [22]. Moreover, thus the hypothetical role of reflux in increasing the risk for cancer development, it should be worthy of investigation 
its potential role in determining cancer recurrence, especially when other factors, such as anatomical alterations.

Currently, there is no consensus regarding the appropriate methodology to identify GPR, because the detection of acid exposure in the upper oesophagus often remains unknown using traditional $\mathrm{pH}-$ monitoring, especially if no pharyngeal probe is used. Thus, level of reflux into the pharynx remains controversial [23]. Impedance monitoring detects change in resistance to the gastric back-flow between two electrodes; when a liquid bolus bridges the two electrode rings, impedance decreases directly with the degree of bolus ionization. In contrast, a gas bolus increases impedance. These differences in impedance characteristics allow differentiation of liquid, gas, and combined liquid-gas (mixed) boluses [24].

The aim of our study was to determine, using objective methodology and criteria, the incidence of GPR in patients who underwent total laryngectomy for oncological reasons. In addition, we looked for associations between levels of reflux and age, gender, smoking habits, drinking habits, occupation, pathological TNM, interval since total laryngectomy (months), type of post-operative radiotherapy (curative or adjuvant) and reflux symptoms. These data will form the foundation for future investigations of the potential incidence of GPR in these patients, about its influence on the development of their possible postoperative complications or the management of a possible secondary neoplasms or cancer recurrence.

\section{Methods}

\subsection{Study population}

We enrolled from a pool of 98 laryngectomised patients who underwent total laryngectomy surgery for advanced laryngeal cancer at our Institution between 2005 and 2010, a small group of 25 patients (18 male and 7 female) with negative clinical history for GPR. The current study was approved by the University of Florence Review Board, and all patients gave a written informed consent to participate.

Previous surgery for gastric cancer or other head and neck cancer, as well as previous radiotherapy or chemotherapy treatments, previous surgical treatment for documented GERD, positive history for GER or pharyngo-laryngeal reflux (PLR) documented by a preoperative double-channel, ambulatory MII/pH-metry-monitoring test, as well as, positive history for antacid medications were criteria for exclusion from the study.

Data were obtained regarding age, gender, time of onset of the advanced laryngeal tumor, place of residence, occupation, smoking history, details of previous surgical interventions, and included an update medical history with information on risk factors and living conditions.

As regards tobacco use, patients were classified as: 1 ) never smokers (no history of cigarette smoking), 2) former smokers (persons who had smoked but had quit before the laryngeal surgery), 3) current smokers (persons who were smoking at the time of the hospital admission). Former and current smokers were also combined as "ever smokers" and number of cigarettes smoked per day and duration of smoking were recorded.

Alcohol intake was reported and classified as: 1) non-drinkers or occasionally drinker, 2 ) social drinkers ( $<36 \mathrm{~g}$ of alcohol per day), 3 ) heavy drinkers ( $>36 \mathrm{~g}$ of alcohol per day).

Postoperative radiotherapy application was divided as: 1) $<50 \mathrm{~Gy}$; 2) >50 Gy. The average time between the laryngectomy and the $\mathrm{pH}$ measurement was 1.4 years (range, $0.5-2.5$ years).

\subsection{Data acquisition}

Each patient underwent a 24-hour, double-channel, ambulatory pHmonitoring study using a Digitrapper MK III ambulatory pH monitor (Synectics Medical AB, Stockholm, Sweden) and Zinetics 24 TM double-channel pH catheters (Zinetics Medical Inc., Salt Lake City, UT) with two pH sensors placed $15 \mathrm{~cm}$ apart. Synectics EsopHagram software PW version 2.04 was used for data analysis. The catheter was introduced trans-nasally, and the lower sensor was positioned $5 \mathrm{~cm}$ above the LES under direct visualization using flexible fiberoptic endoscope as described by Vincent et colleagues [25]. pH recordings were made for approximately $24 \mathrm{~h}$, and cutoff values (percentages of time at a certain pH level) were established for the lower and upper sensor measurements based on our laboratory's normal values. The cutoff values for the lower (distal) sensor were $4.7 \%$ of total time at $\mathrm{pH}<4$, $5.1 \%$ of total upright time at $\mathrm{pH}<4$, and $5.2 \%$ of total supine time at $\mathrm{pH}$ $<4$. The cutoff values for the upper (proximal) sensor were $1.4 \%$ of total time at $\mathrm{pH}<4,1.9 \%$ of total upright time at $\mathrm{pH}<4$, and $1.3 \%$ of total supine time at $\mathrm{pH}<4$. Patients with values above these limits were considered to have pathologic acid reflux.

The $2.1 \mathrm{~mm}$ diameter catheter, was secured to the nasal dorsum with an adhesive strap, and it comprised of 6 electrode pairs measuring intraluminal impedance at 3,5,7,9,15 and $17 \mathrm{~cm}$ above the LES and an antimony $\mathrm{pH}$ sensor at $5 \mathrm{~cm}$ above the LES. The signals form 6 pairs impedance channel and $1 \mathrm{pH}$ channel are recorded at 5 samples per second.

During the $24 \mathrm{~h}$ monitoring period, patients were asked to keep a diary of all oral intake except water and to specify other information such as meal time, intervals spent in the supine, upright and recumbent position. Patients were asked to avoid frequent snacks and gum chewing between main meals, also to refrain from taking antacid medications for a minimum of $72 \mathrm{~h}$ before examination.

Collected data were uploaded to a personal computer using the Polygram for Windows with the Esophagram Reflux Analysis Module version 2.05 software package (medtronic Functional Diagnostics, Inc., Skovlunde, Denmark).

\subsection{Scoring of reflux episodes}

Reflux episode was defined as either pure liquid or a mixture of liquid and gas detected by impedance. Liquid only reflux was defined as a $50 \%$ of fall in impedance from baseline value in the 2 distal impedance sites [26]. Gas reflux was associated to a simultaneous increase in impedance higher than $3000 \Omega$ in any of two consecutive impedance sites with one site having an absolute value higher than $7000 \Omega$. Mixed liquid and gas reflux was defined as gas reflux occurring during or immediately before liquid reflux [27].

For the distal probe Richter's criteria were used to distinguish between physiologic and pathologic reflux by defining as normal $\mathrm{pH}$ below $4<5.5 \%$ of the total time, $<8.2 \%$ of the time in upright positions and $<3.0 \%$ of the time in supine positions [28]. For the proximal probe, normal values used were any period of $\mathrm{pH}<4$ found at the level of the upper esophageal sphincter (UES) [24].

Reflux episodes were characterized by three different values of $\mathrm{pH}$ defined respectively as: 1 ) acid $(\mathrm{pH}<4), 2$ ) weakly acid ( $\mathrm{pH}$ between 4 and 7$)$ and, 3 ) alkaline $(\mathrm{pH}>7)$. For each reflux episode detected by impedance, bolus exposure at $5 \mathrm{~cm}$ above LES was calculated as the time between the $50 \%$ of drop in impedance until the $50 \%$ of recovery of the impedance baseline value and lasting for at least $5 \mathrm{~s}$. Proximal reflux was defined as reflux reaching $15 \mathrm{~cm}$ impedance site above LES. Impedance-pH tracings were analyzed during both upright and supine position, which was defined as a reclining position at an angle $<45$ degrees.

Acid exposure was conventionally defined as total time $\mathrm{pH}<4$ divided by the time monitored. Bolus exposure (\%) is a parameter was defined analogously to acid exposure by adding the duration of all three reflux subcategories defined by impedance and dividing this value by time monitored [27].

Analysis of the parameters included: total number of reflux episodes, number of reflux episodes as regards of composition (liquid, gas and mixed reflux episodes) and $\mathrm{pH}$ (acid, weakly acid and alkaline), bolus clearance time, bolus exposure and proximal reflux episodes. 


\subsection{Statistical analysis}

To avoid erroneous inclusion of reflux events during meals, all events that occurred during eating intervals and within 2 min after the recorded meal end time were excluded from analysis. Continuous variables are expressed as mean $\pm \mathrm{SD}$, and comparison of categorical variables were performed by Pearson's $\chi^{2}$ test; a p value $<0.05(2-$ tailed) was considered significant. Logistic regression models were used to assess the association between the incidence of GPR and variables such as: age, gender, smoking habits, drinking habits, reflux symptoms, occupation, interval since total laryngectomy (months), postoperative radiotherapy, pathological TNM and type of neck dissection associated with the total laryngectomy. All results from logistic models are expressed as Odds Ratio. Analyses were performed with STATA System software.

\section{Results}

\subsection{Study population}

18 (72\%) patients were men and 7 (18\%) were women, out of the 25 patients enrolled in the study. The median age was $63.24 \pm 8.66 \mathrm{SD}$ years (range, $46-80$ years; $59.69-66.81 \mathrm{CI}$ ). Only one patient (4\%) had never smoked, 6 patients (24\%) were former smokers, and $18(72 \%)$ were current smokers. The $20 \%$ of patients were non-drinkers, while the $52 \%$ were social drinkers and the $18 \%$ reported a history of heavy alcohol abuse. 5 out of the 25 patients (20\%) were white-collar workers, the $20 \%$ of were blue-collar workers, and the remaining $60 \%$ belong to other categories.

All patients were affected by advanced laryngeal squamous-cell carcinoma (T3 or T4), histologically confirmed. 9 patients (36\%) had a T3 laryngeal lesion, 16 patients (64\%) had a T4 laryngeal cancer. 4 out of 25 (16\%) were classified as III stage and the remaining 21 (84\%) were IV stage. All of them underwent total laryngectomy and adjuvant post-operative radiotherapy ( $<50 \mathrm{~Gy}$ ) was performed in 12 out of 25 patients (48\%) while the remaining 13 patients underwent curative radiotherapy (>50 Gy) (52\%).

Postoperative reflux symptoms (heartburn, pharyngitis, globus sensation, sinusitis, otalgia, etc.) were claimed by a total amount of 8 (32\%) patients out of 25.

The mean clinical follow-up time was of $76.48 \pm 21.26$ SD (range, 48-120 months; 67.70-85.26 CI).

None significant association was found between incidence of GPR and any of the clinical characteristics studied (Table 1).

\subsection{Impedance findings}

Reflux $5 \mathrm{~cm}$ above LES was more common during the upright position than in recumbent position $(\mathrm{p}<0.0001)$. The total amount of pathological episodes of reflux was recorded in 10 out of 25 patients (40\%).

Bolus duration last $12 \mathrm{~s}$ on average by impedance, and showed a medium duration of $13.3 \mathrm{~s}$ for upright and $9 \mathrm{~s}$ for recumbent reflux. These short bolus durations resulted in a total bolus exposure of only $2.4 \%$, with a final total amount of pathological records of $36 \%$.

On the other hand, reflux episodes were much more common in upright than in recumbent position $15 \mathrm{~cm}$ above the LES $(\mathrm{p}<0.0001)$. In fact, the proximal oesophagus was reached by a mean value of 34.68 \pm 12.92 SD of reflux episodes by impedance in the upright position, in contrast with a median of 6 episodes recorded in the recumbent position.

Median bolus exposure at the proximal sphincter was 25\% lower than $5 \mathrm{~cm}$ above the LES (3.4\% versus $4.4 \%)(p=0.3593)$.

All of these data are reported in Table 2.

The analysis of the acid exposure $5 \mathrm{~cm}$ above the LES showed a pathologic value in 16 out of 25 patients (64\%). Total acid reflux frequency
Table 1

Shows the characteristics of the study population.

\begin{tabular}{|c|c|c|}
\hline Clinical characteristics & Patients (number) & Percentage (\%) \\
\hline \multicolumn{3}{|l|}{ Gender } \\
\hline Male & 18 & 0,72 \\
\hline Female & 7 & 0,18 \\
\hline \multicolumn{3}{|l|}{ Smoking status } \\
\hline Never & 1 & 0,04 \\
\hline \multicolumn{3}{|l|}{ Former } \\
\hline$<10$ cig/day & 1 & $4 \%$ \\
\hline$>10$ ci/day & 5 & $21 \%$ \\
\hline \multicolumn{3}{|l|}{ Current } \\
\hline$<10$ cig/day & 1 & $4 \%$ \\
\hline $10-20 \mathrm{cig} /$ day & 9 & $37 \%$ \\
\hline$>20 \mathrm{cig} / \mathrm{day}$ & 8 & $34 \%$ \\
\hline \multicolumn{3}{|l|}{ Alcohol consumption } \\
\hline Non-drinkers & 5 & 0,2 \\
\hline Social drinkers & 13 & 0,52 \\
\hline Heavy drinkers & 7 & 0,25 \\
\hline \multicolumn{3}{|l|}{ Occupation } \\
\hline White collar & 5 & 0,2 \\
\hline Blue collar & 5 & 0,2 \\
\hline Others & 15 & 0,6 \\
\hline Postoperative reflux symptoms & 8 & 0,32 \\
\hline \multicolumn{3}{|l|}{ TNM } \\
\hline T3 & 9 & 0,36 \\
\hline $\mathrm{T} 4$ & 16 & 0,64 \\
\hline NO & 2 & 0,08 \\
\hline N1 & 5 & 0,2 \\
\hline $\mathrm{N} 2 \mathrm{a}$ & 9 & 0,36 \\
\hline $\mathrm{N} 2 \mathrm{~b}$ & 6 & 0,24 \\
\hline $\mathrm{N} 2 \mathrm{c}$ & 2 & 0,08 \\
\hline N3 & 1 & 0,04 \\
\hline \multicolumn{3}{|l|}{ Stage } \\
\hline III & 4 & 0,16 \\
\hline IV & 21 & 0,84 \\
\hline \multicolumn{3}{|l|}{ Postoperative radiotherapy } \\
\hline$<50$ Gy & 12 & 0,48 \\
\hline$>50 \mathrm{~Gy}$ & 13 & 0,52 \\
\hline
\end{tabular}

was at least three-fold more likely than weakly acid or nonacid reflux in our series at both esophageal sphincters $(p<0.0001)$.

The $40 \%$ of patients presented a pathologic exposure to acid reflux, while only 8 out of 25 (32\%) had pathologic weakly acid reflux episodes. The analysis of reflux content in our cohort of patients showed a prevalence of liquid reflux episodes at $5 \mathrm{~cm}$ above the LES, where the pathologic value was reported by 11 out of 25 patients (44\%), and it was statistically significant against the frequency of reflux containing both liquid and gas ( $\mathrm{p}=0.003)$.

Nine patents out of 25 (36\%) presented mixed pathologic values of reflux, while the $44 \%$ of patients had a total amount of pathologic content of reflux episodes.

Table 2

24-hour impedance-pH reflux episodes recorded $5 \mathrm{~cm}$ and $15 \mathrm{~cm}$ above the LES in 25 patients.

\begin{tabular}{|c|c|c|c|c|}
\hline & \multicolumn{2}{|c|}{ Reflux episodes } & \multicolumn{2}{|c|}{$\%$ bolus exposure } \\
\hline & $\begin{array}{l}5 \mathrm{~cm} \text { above } \\
\text { LES }\end{array}$ & $\begin{array}{l}15 \mathrm{~cm} \text { above } \\
\text { LES }\end{array}$ & $\begin{array}{l}5 \mathrm{~cm} \text { above } \\
\text { LES }\end{array}$ & $\begin{array}{l}15 \mathrm{~cm} \text { above } \\
\text { LES }\end{array}$ \\
\hline \multicolumn{5}{|l|}{ Total 24-h } \\
\hline $\begin{array}{l}\text { Median (mean } \pm \\
\quad \text { SD) }\end{array}$ & $\begin{array}{l}76(64.4 \pm \\
31.63)\end{array}$ & $\begin{array}{l}41(40.84 \pm \\
16.41)\end{array}$ & $\begin{array}{l}2.4(3.380 \pm \\
2.416)\end{array}$ & $\begin{array}{l}2.7(2.816 \pm \\
1.350)\end{array}$ \\
\hline 95th percentile & 80 & 47 & 4.4 & 3.4 \\
\hline \multicolumn{5}{|l|}{ Upright } \\
\hline $\begin{array}{l}\text { Median (mean } \pm \\
\quad \text { SD) }\end{array}$ & $\begin{array}{l}69(60.32 \pm \\
28.54)\end{array}$ & $\begin{array}{l}37(34.68 \pm \\
12.92)\end{array}$ & $\begin{array}{l}1.7(2.672 \pm \\
2.174)\end{array}$ & $\begin{array}{l}2.1(2.384 \pm \\
1.181)\end{array}$ \\
\hline 95th percentile & 72 & 40 & 3.6 & 2.8 \\
\hline \multicolumn{5}{|l|}{ Recumbent } \\
\hline $\begin{array}{l}\text { Median (mean } \pm \\
\quad \text { SD) }\end{array}$ & $6(7 \pm 5.25)$ & $\begin{array}{l}6(6.16 \pm \\
6.29)\end{array}$ & $\begin{array}{l}0.7(0.708 \pm \\
0.445)\end{array}$ & $\begin{array}{l}0.3(0.432 \pm \\
0.322)\end{array}$ \\
\hline 95th percentile & 9 & 8 & 0.9 & 0.56 \\
\hline
\end{tabular}


On the other hand, there was a prevalence of mixed reflux at the UES in comparison to the LES, about two-fold higher than the median value of liquid reflux. The consequent number of pathologic mixed reflux episodes was of 11 out of 25 (44\%). The statistical comparison between the two type of reflux contents was significant $(\mathrm{p}=0.0001)$, with a global value of pathologic events of $40 \%$.

All of these impedance parameters are reported in Table 3.

\section{3. $\mathrm{pH}$ probe findings}

Total acid exposure mean value was $7.5 \%$, virtually divided into $5.2 \%$ in the upright position and $2 \%$ in the recumbent one. Fourteen patients out of 25 (56\%) had a pathological percentage time of acid exposure.

$\mathrm{pH}$-only reflux episodes (REs), defined as a $\mathrm{pH}$ fall from above to below 4 in the absence of reflux detected by impedance monitoring were recorded in 13 of the 25 patients (52\%), with a median episodes of REs of 11.4. Median total REs as measured by pH was 1.5 time greater than total acid exposure measured by impedance $(\mathrm{p}=0.0013)$.

All patients tolerated the procedure well and completed the $24 \mathrm{~h}$ study without experiencing adverse effects (Table 4).

\section{Discussion}

In our opinion, total laryngectomy deeply modifies the anatomy and the physiology of the upper airways digestive tract. In fact, our finding of high incidence of GPR and GER in the laryngectomised patients might be explained with the disturbance of the complex antacid barrier, such as, the LES tone, esophageal acid clearance, esophageal epithelial resistance and the absence of an upper esophageal sphincter (UES) which has been removed during surgery and that has been replaced by a neopharynx which has not the same muscular tone [22]. Salivary secretion also influences the anti-reflux barrier. Moreover, during laryngectomy, neurectomy of the pharyngeal plexus and myotomy of the cricopharyngeal muscle are performed to facilitate post-surgical voice rehabilitation. These procedures, aimed at decreasing the tone of the neopharynx, may simultaneously decrease one of the last antacid barriers for GPR [22]. Consequentially, total laryngectomy is potentially able to generate reflux or, at least, to potentiate its harmful action on pharyngeal mucosa. Furthermore, radiotherapy for head and neck malignancies influences the salivary secretion, thereby compromising another reflux barrier [22,29,30].

Whereas, all of these hypotheses do not find concordant and final conclusions in literature so far, we performed this study to improve the knowledge of GPR onset and effects on a specific group of patients.

We used a population-based cohort design with a negative history for GER before surgery, the complete assessment of the exposure and the outcomes, the long and complete follow-up, and the measuring of the presence of reflux with the dual channel combined MII/pH-metry, a new method that allows detection and classification of all reflux events and to evaluate the extent of reflux episodes.

According to literature [31] acid reflux events detected by impedance were much shorter than those measured by $\mathrm{pH}$. The explanation for this has been that neutralization of acid takes longer than volume

\section{Table 4}

pH-parameters of 25 cases.

\begin{tabular}{lll}
\hline & pH parameters \\
\cline { 2 - 3 } & Reflux episodes & \\
\cline { 2 - 3 }$\%$ time acid exposure & pH-only reflux episodes (REs) \\
\hline Total 24-h & $7.5(8.08 \pm 3.635)$ & $11.4(11.9 \pm 4.673)$ \\
$\begin{array}{l}\text { Median } \\
\text { 95th percentile }\end{array}$ & 8 & 12 \\
Upright & & \\
Median & $5.2(6.3 \pm 3.34)$ & $8.4(9.5 \pm 4.59)$ \\
95th percentile & 6 & 10 \\
$\begin{array}{l}\text { Recumbent } \\
\text { Median }\end{array}$ & $2(1.788 \pm 0.839)$ & $2.2(2.396 \pm 1.057)$ \\
95th percentile & 3 & 3 \\
\hline
\end{tabular}

clearance. Initial studies using impedance and $\mathrm{pH}$ measurements demonstrated that many reflux events are missed by $\mathrm{pH}$, using acid reflux definitions, while MII had higher detection rates for reflux events than $\mathrm{pH}$ monitoring [32]. The high number of reflux episodes detected by the proximal probe shows that our cohort of laryngectomised patients had a pathologic GPR developed after the operation, with a significant $\mathrm{p}$ value of reflux episodes in the upright positions at both levels above the LES ( $p<0.0001$ ) in the $40 \%$ of patients, and this is in line with those limited number of studies reported in literature [24,33,34]. Although dual-channel 24-h pH monitoring with esophageal and pharyngeal $\mathrm{pH}$ probes has been shown to be able to detect GPR [35,36], in the dedicated literature the vast major of its use has been performed in not treated head and neck cancer patients [37], moreover several methodological problems, like poor sensibility of the pharyngeal probe secondary to the relatively alkaline environment of proximal aero-digestive tract, have plagued the ability of researchers to measure reflux in the hypopharynx and the current evidence basis for the association is weak. For example, Koufmura et colleagues [35] have characterized GPR using MII-pH as predominantly pure gas events, on the contrary, in our cohort of patients the physical analysis of the refluxate at $15 \mathrm{~cm}$ above LES showed a prevalence of mixed reflux events $(p=0.0001)$ while at $5 \mathrm{~cm}$ there was a prevalence of liquid reflux episodes ( $\mathrm{p}=$ 0.003).

Our multivariate analysis showed no significant association among clinical characteristics of the study population and the onset of reflux symptoms after the operation of total laryngectomy, but the finding of a high incidence of reflux after total laryngectomy indicates that, in accordance with literature, reflux should be investigated and scored in order to better manage complications that might occur after surgery, during radiotherapy, and in voice rehabilitation. For example, there are some reports in literature that declare a significant correlation between the occurrence of thacheo-esophageal fistula complications, together with pulmonary distress, and the severity of supra-esophageal reflux in laryngectomised patients [33,38-42]. In this scenario, pathological gastro-pharyngeal reflux appears among the possible causes of speech fistula enlargement together with local inflammatory responses in the region of the fistula, atrophy of the tissue around the fistula as a

Table 3

24-hour impedance-pH frequency of reflux type episodes and their content recorded $5 \mathrm{~cm}$ and $15 \mathrm{~cm}$ above the LES in 25 patients.

\begin{tabular}{|c|c|c|c|c|c|c|}
\hline & \multicolumn{6}{|c|}{ Impedance parameters } \\
\hline & \multicolumn{3}{|c|}{ Frequency of reflux type } & \multicolumn{3}{|c|}{ Content of reflux episodes } \\
\hline & Acid & Weakly acidic & Nonacid & Liquid & Mixed & Total \\
\hline \multicolumn{7}{|l|}{$5 \mathrm{~cm}$ above the LES } \\
\hline Median (mean \pm SD) & $63(54.76 \pm 21.0)$ & $12(15.76 \pm 8.2)$ & $1(1.68 \pm 1.95)$ & $47(41.6 \pm 20.44)$ & $28(25.64 \pm 15.6)$ & $73(67.08 \pm 30.45)$ \\
\hline 95th percentile & 63 & 19 & 2 & 50 & 32 & 79 \\
\hline \multicolumn{7}{|l|}{$15 \mathrm{~cm}$ above the LES } \\
\hline Median $($ mean \pm SD) & $31(30.84 \pm 10.49)$ & $10(10.76 \pm 6.52)$ & $1(1.64 \pm 1.63)$ & $14(14.12 \pm 6.81)$ & $27(28.08 \pm 12.92)$ & $40(42.24 \pm 17.63)$ \\
\hline 95th percentile & 35 & 13 & 2 & 17 & 33 & 50 \\
\hline
\end{tabular}


result of adjuvant radiotherapy, micro-movements of the prosthesis and trauma in the region of the fistula during prosthesis replacement procedures [43]. These findings are supported by several results, which show a significantly higher incidence of esophageal or supraesophageal reflux events in patients who have undergone partial or total laryngectomy $[22,44]$. Thus the lack of protective mechanisms against gastric acid exposure, even minor exposure of the trachea, can lead to massive damage, which may be caused by a low $\mathrm{pH}$ value, pepsin, pancreatic enzymes, and bile acid $[3,45]$. Even if the risk of periprosthetic leakage and fistula enlargement seems to rise up to 2.3 times higher in patients with pathologic reflux, the complete resolution of peri-prosthetic complications has been documented in $>70 \%$ of patients who have been taking oral proton pomp inhibitors (PPIs) for at least 6 consecutive months [38,43,46-48]. Recently, Stephenson and colleagues have confirmed the presence of a statistically significant reduction in fistulae with PPI prophylaxis, as well, suggesting to perform further research to better define the role of reflux in laryngeal cancer patients management [49]. Hence, to be aware of the incidence of GPR after laryngeal surgery could help surgeons in preventing postoperative complications, short-term and long-term sequelae, and the awareness of the reflux possible cancerogenic effect might help in screening risk for cancer recurrence during the follow-up.

In fact, another issue regarding GPR and total laryngectomy, which deserves to be mentioned, is the role of reflux in laryngeal cancer recurrence. To our knowledge there is only one study in literature that investigates the incidence of cancer recurrence and presence of GPR [50] which showed in laryngeal cancer patients, previously treated with conservative surgery or radiotherapy/chemotherapy, that the recurrence was significantly less frequent in those who were on acid suppressive therapy by PPI medication, suggesting it may have a protective effect in preventing cancer recurrence. This reflects the same principle declared by Langevin et al. [15] who found a consistent inverse association between antacid use and LPSCCs in patients suffering from heartburn; however there are no prospective randomized phase III trial confirming this.

Although based on a limited number of studies, there are data to support an association between total laryngectomy and risk of postoperative complications. And, aggressive treatment with PPI medications has been reported to led to an improvement in reflux symptoms both in diagnostic tests and in the clinical setting. Despite these findings, the biological mechanism behind a possible association between total laryngectomy and these events is still uncertain. However, an independent role of GER is not completely ruled out, thus it might increase the vulnerability of the mucosa for such reflux exposure [51-53].

In conclusion, on the basis of these results we can assume that all laryngectomised patients should be treated with acid suppressive therapy because of the high risk for presence of pathologic reflux findings. Further supports may clarify the role of GPR in post-operative complications like pharyngotracheal and pharyngocutaneous fistula, wound dehiscence and difficulties in the management of voice prothesis or the contribution of GPR to the development of secondary neoplasms or cancer recurrence. Again, due to its crucial role on prognosis and quality of life of the patient, the preoperative assessment of GPR and follow up after surgery may elucidate the impact of reflux on treatment outcomes and clinical follow-up, and this might represent the object of future perspective studies.

Based on our findings, we consider prophylactic treatment with PPIs to be justified in all patients undergoing laryngeal surgery or during radiotherapy even if they have no previous history of GER.

\section{Conflicts of interest}

None.

\section{Acknowledgements}

This manuscript was approved by all of the authors and all of the authors participated in writing and correcting this work. Furthermore, all of the authors assure that manuscript has not been published nor is under consideration by other journals or editors and that they have no conflicts of interest, financial or otherwise.

\section{References}

[1] Nilsson M, Chow WH, Lindblad M, et al. No association between gastresophageal reflux and cancers of the larynx and pharynx. Cancer Epidemiol Biomarkers Prev 2005;14:1194-7.

[2] Locke III GR, Talley NJ, Fett SL, et al. Prevalence and clinical spectrum of gastresophageal reflux: a population-based study in Olmsted County, Minnesota. Gastroenterology 1997:112:1448-56.

[3] Koufman JA. The otolaryngologic manifestations of gastresophageal reflux disease (GERD): a clinical investigation of 225 patients using ambulatory 25-hour $\mathrm{pH}$ monitoring and an experimental investigation of the role of acid and pepsin in the development of laryngeal injury. Laryngoscope 1991;101(Suppl. 53):1-78.

[4] El-Serag HB, Hepworth EJ, Lee P, et al. Gastresophageal reflux disease is a risk factor for laryngeal and pharyngeal cancer. Am J Gastroenterol 2001;96:2013-8.

[5] Freije JE, Beatty TW, Campbell BH, et al. Carcinoma of the larynx in patients with gastresophageal reflux. Am J Otolaryngol 1996;17:386-90.

[6] Galli J, Cammarota G, De Corso E, et al. Biliary laryngopharyngeal reflux: a new pathological entity. Curr Opin Otolaryngol Head Neck Surg 2006;14:128-32.

[7] Champion GL, Richter JE. Atypical presentation of gastresophageal reflux disease: chest pain, pulmonary, and ear, nose, throat manifestations. Gastroenterologist 1993;1:18-33.

[8] Garrigues V, Gisbert L, Bastida G, et al. Manifestations of gastresophageal reflux and response to omeprazole therapy in patients with chronic posterior laryngitis: an evaluation based on clinical practice. Dig Dis Sci 2003;48:2117-23.

[9] Maronian N, Haggitt R, Oelschlager BK, et al. Histologic features of reflux-attributed laryngeal lesions. Am J Med 2003;115(Suppl 3A):105S-8S.

[10] Tae K, Jin BJ, Ji YB, et al. The role of laryngopharyngeal reflux as a risk factor in laryngeal cancer: a preliminary report. Clin Exp Otorhinolaryngol 2011;4:101-4.

[11] Morrison MD. Is chronic gastresophageal reflux a causative factor in glottic carcinoma? Otolaryngol Head Neck Surg 1998;99:370-3.

[12] Biacabe B, Gleich LL, Laccourreye O, et al. Silent gastresophageal reflux disease in patients with pharyngolaryngeal cancer: further results. Head Neck 1998;20:510-4.

[13] Ward PH, Hanson DG. Reflux as an etiological factor of carcinoma of the laryngopharynx. Laryngoscope 1988;98:1195-9.

[14] Wilson JA. What is the evidence that gastresophageal reflux is involved in the etiology of laryngeal cancer? Curr Opin Otolaryngol Head Neck Surg 2005:13:97-100.

[15] Langevin SM, Michaud DS, Marsit CJ, et al. Gastric reflux is an independent risk factor for laryngopharyngeal carcinoma. Cancer Epidemiol Biomarkers Prev 2013;22:1061-8.

[16] Zhang D, Zhou J, Chen B, et al. Gastresophageal reflux and carcinoma of larynx or pharynx: a meta-analysis. Acta Otolaryngol 2014;134:982-9.

[17] Lagergren J, Lindam A. Increased risk of laryngeal and pharyngeal cancer after gastrectomy for ulcer disease in a population-based cohort study. BJC 2012;27(106): 1342-5.

[18] Cann CI, Fried MP, Rothman KJ. Epidemiology of squamous cell cancer of the head and neck. Otolaryngol Clin North Am 1985;18:367-88.

[19] Koufman JA, Burke AJ. The etiology and pathogenesis of laryngeal carcinoma. Otolaryngol Clin North Am 1997;30:1-19.

[20] Lagergren J, Bergstrom R, Lindgren A, et al. Symptomatic gastroesophageal reflux as a risk factor for esophageal adenocarcinoma. NEJM 1999;340:825-31.

[21] Farrow DC, Vaughan TL, Sweeney C, et al. Gastresophageal reflux disease, use of H2 receptor antagonists, and risk of esophageal and gastric cancer. Cancer Causes Control 2000;11:231-8.

[22] Smit CF, Tan J, Mathus-Vliegen LMH, et al. High incidence of gastropharyngeal and gastresophageal reflux after total laryngectomy. Head Neck 1998;20:619-22.

[23] Lewin JS, Gillenwater AM, Garrett JD, et al. Characterization of laryngopharyngeal reflux in patients with premalignant or early carcinoma of the larynx. Cancer 2003;97: 110-4.

[24] Smit CF, Tan J, Devriese PP, et al. Ambulatory pH monitoring at the upper esophageal sphincter. Laryngoscope 1998;108:299-302.

[25] Vincent DA, Garrett JD, Radionoff SL, et al. The proximal probe in esophageal $\mathrm{pH}$ monitoring: development of a normative database. J Voice 2000;14:247-54

[26] Vela M, Camacho-Lobato L, Srinivasan R, et al. Simultaneus intraesophageal impedance and $\mathrm{pH}$ measurement of acid and nonacid gastresophageal reflux: effect of omeprazole. Gastroenterology 2001;120:1599-606.

[27] Shay S, Tutuian R, Sifrim D, et al. Twenty-four hour ambulatory simultaneus impedance and pH monitoring: a multicentric report of normal values from 60 healthy volunteers. Am J Gastroenterol 2004;99:1037-43.

[28] Richter JE, DeMeester TR, Wu WC, et al. Normal 24-hour esophageal pH values: influence of age and gender. Gastroenterology 1990;98:A122.

[29] Mercadante V, Al Hamad A, Lodi G, et al. Interventions for the management of radiotherapy-induced xerostomia and hyposalivation: a systematic review and meta-analysis. Oral Oncol 2017;66:64-74.

[30] Marangoni-Lopes L, Rodrigues LP, Mendonça RH, et al. Radiotherapy changes salivary properties and impacts quality of life of children with Hodgkin disease. Arch Oral Biol 2016;72:99-105.

[31] Wise JL, Murray JA. Utilising multichannel intraluminal impedance for diagnosing GERD: a review. Dis Esophagus 2007;20:83-8.

[32] Shay S, Richter J. Direct comparison of impedance, manometry and pH probe in detecting reflux before and after a meal. Dig Dis Sci 2005;5:1584-90.

[33] Lorenz KJ, Grienser L, Ehrhart T, et al. Role of reflux in tracheesophageal fistula problems after laryngectomy. Ann Otol Rhinol Laryngol 2010;119:719-28. 
[34] LeBlanc B, Lewis E, Caldito G, et al. Increased pharyngeal reflux in patients treated for laryngeal cancer: a pilot study. Otolaryngol Head Neck Surg 2015;153:791-4.

[35] Koufmura O, Aslam M, Rittmann T, et al. Laryngopharyngeal reflux: position statement of the committee on speech, voice and swallowing disorders of the American Academy of Otolaryngology-Head and Neck Surgery. Otolaryngol Head Neck Surg 2002;127:32-5.

[36] Ozlugedik S, Yorulmaz I, Gokcan K. Is laryngopharyngeal reflux an important risk factor in the development of laryngeal carcinoma? Eur Arch Otorhinolaryngol 2006;263:339-43.

[37] Copper MP, Smit CF, Stanojcic LD, et al. High incidence of laryngopharyngeal reflux in patients with head and neck cancer. Laryngoscope 2000;110:1007-11.

[38] Seikaly H, Park P. Gastresophageal reflux prophylaxis decreases the incidence of pharyngocutaneous fistula after total laryngectomy. Laryngoscope 1995;105: $1220-2$.

[39] Sontag SJ. Gastresophageal reflux and asthma. Am J Med 1997;103:84S-90S.

[40] Lorenz KJ, Ehrhart T, Grieser L, et al. Coincidence of fistula enlargement and supraesophageal reflux in patients after laryngectomy and prosthetic voice restoration. HNO 2009;57:1253-61.

[41] Hilgers FJM, Soolsma J, Ackerstaff AH, et al. A thin tracheal silicone washer to solve periprosthetic leakage in laryngectomies: direct results and longterm clinical effects. Laryngoscope 2008;4:640-5.

[42] Malik T, Bruce I, Cherry J. Surgical complications of tracheo-esophageal puncture and speech valves. Curr Opin Otolaryngol Head Neck Surg 2007;2:117-22.

[43] Lorenz KJ, Grieser L, Ehrhart T, et al. The management of periprosthetic leakage in the presence of supra-esophageal reflux after prosthetic voice rehabilitation. Eur Arch Otorhinolaryngol 2011;268:695-702.
[44] Marìn Garrido C, Fernàndez Liesa $R$, Vallès Varela $H$, et al. Study of laryngopharyngeal reflux using $\mathrm{pH}$-metering in immediate post-op of laryngectomized patients. Acta Otorrinolaringol Esp 2007;58:284-9.

[45] Bock JM, Brawley MK, Johnston N, et al. Analysis of pepsin in tracheesophageal puncture sites. Ann Otol Rhinol Laryngol 2010;119:799-805.

[46] Jobe BA, Rosenthal E, Wiesberg TT, et al. Surgical management of gastresophageal reflux and outcome after laryngectomy in patients using tracheesophageal speech. Am J Surg 2002;183:539-43.

[47] Lorenz KJ, Kraft K, Graf F, et al. Role of reflux-induced epithelial-mesenchymal transition in periprosthetic leakage after prosthetic voice rehabilitation. Head Neck 2015;37:530-6.

[48] Cocuzza S, Bonfigio M, Chiaramonte R, et al. Gastresophageal reflux disease and postlaryngectomy tracheesophageal fistula. Eur Arch Otorhinolaryngol 2012;269: 1483-8.

[49] Stephenson KA, Fagan JJ. Effect of perioperative proton pump inhibitors on the incidence of pharyngocutaneous fistula after total laryngectomy: a prospective randomized controlled trial. Head Neck 2015;37:255-9.

[50] Qadeer MA, Lopez R, Wood BG, et al. Does acid suppressive therapy reduce the risk of laryngeal cancer recurence? Laryngoscope 2005;115:1877-81.

[51] Qadeer MA, Colabianchi N, Vaezi MF. Is GERD a risk factor for laryngeal cancer? Laryngoscope 2005;115:486-91.

[52] Oadeer MA, Colabianchi N, Strome M, et al. Gastresophageal reflux and laryngeal cancer: causation or association? A critical review. Am J Otolaryngol Head Neck Med Surg 2006;27:119-28.

[53] Glanz H, Kleinsasser O. Chronic laryngitis and carcinoma (author's transl). Arch Otorhinolaryngol 1976;212:57-75. 